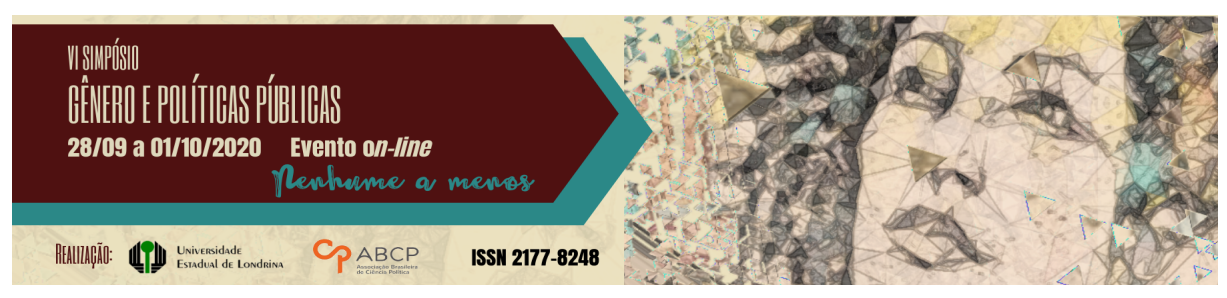

\title{
O ambiente escolar e a divisão sexual nas ciências exatas: um relato de experiência
}

\author{
Daniele Costa Silva ${ }^{1}$
}

\section{Resumo}

O presente trabalho tem como objetivo relatar e discutir acerca de experiências relacionadas ao projeto de extensão "ELAS na UTFPR-CP", uma iniciativa de docentes e estudantes da Universidade Tecnológica Federal do Paraná, Câmpus Cornélio Procópio, realizada de outubro de 2017 a setembro de 2018, que visava colocar estudantes de escolas públicas de Cornélio Procópio em contato com temas, profissionais e estudantes da área de ciências exatas, tecnologia e engenharia, com intuito de promover o debate sobre a subrepresentatividade feminina nestas áreas, além da compreensão de que mulheres podem ingressar em diferentes carreiras e empoderamento por meio da representatividade feminina e debates sobre gênero. O desenvolvimento do projeto propiciou vivências e enfrentamentos os quais evidenciaram o quão é urgente a discussão acerca da reprodução e projeção de estereótipos e expectativas de gênero no âmbito escolar.

Palavras-chave: gênero; ciências exatas; ambiente escolar.

\section{The school environment and the sexual division in the exact sciences: an experience report}

\footnotetext{
1 Professora do Departamento Acadêmico de Matemática da Universidade Tecnológica Federal do Paraná (UTFPR), Campus Cornélio Procópio; Doutora em Engenharia Elétrica pelo Programa de Pós-Graduação da Faculdade de Engenharia Elétrica e de Computação (FEEC) da Universidade Estadual de Campinas (UNICAMP). E-mail: danielesilva@utfpr.edu.br.
}

GT 02 - Epistemologia feminista: reflexões no Ensino de Ciências 


\begin{abstract}
This paper aims to report and discuss experiences related to the extension project "ELAS na UTFPR-CP", an initiative of professors and students of the Federal Technological University of Paraná, Campus Cornélio Procópio, held from October 2017 to September 2018 , which aimed to put students from public schools in Cornélio Procópio in contact with themes, professionals and students in the area of exact sciences, technology and engineering, with the aim of promoting the debate on the female under-representation of these areas, in addition to understanding that women they can enter different careers and empowerment through female representation and gender debates. The development of the project led to experiences and confrontations which showed how urgent the discussion on the reproduction and projection of gender stereotypes and expectations in the school environment.
\end{abstract}

Keywords: gender; exact sciences; school environment.

\title{
Introdução
}

A presença de mulheres em cursos de ciências exatas, engenharia e tecnologia ainda é pouco significativa em termos quantitativos. Um exemplo deste cenário, é o Câmpus de Cornélio Procópio da Universidade Tecnológica Federal do Paraná (UTFPR), no qual são ofertados 8 cursos de graduação nessas áreas, e apenas cerca de $20 \%$ dos estudantes destes cursos são mulheres.

Esse número reduzido leva a questionamentos acerca do papel da socialização nesse fenômeno, do quanto os estereótipos e expectativas de gênero projetadas pela família e escola interferem no interesse profissional dos estudantes, e da importância de ações que permitam a reflexão sobre como práticas cotidianas podem estar reforçando papéis de gênero e limitando o potencial de meninas para exatas. Nesse contexto, nasce o projeto de extensão "ELAS na UTFPR$\mathrm{CP}^{\prime \prime}$, uma iniciativa de educadoras da UTFPR, Câmpus Cornélio Procópio, realizada de outubro de 2017 a setembro de 2018, a qual visava colocar estudantes de escolas públicas de Cornélio Procópio em contato com temas, profissionais e estudantes da área de ciências exatas, 
tecnologia e engenharia, com intuito de promover o debate sobre a subrepresentatividade feminina nestas áreas, além da compreensão de que mulheres podem ingressar em diferentes carreiras e empoderamento por meio da representatividade feminina e debates sobre gênero.

Para tanto, o projeto foi estruturado de forma a oferecer a estudantes do ensino médio oficinas de gênero nas quais seriam abordados temas relacionados à gênero, sexualidade e feminismo, e oficinas técnicas voltadas apenas às meninas, uma vez que as mulheres são as que mais sofrem os impactos da estereotipação de gênero nas carreiras de ciências exatas, engenharia e tecnologia, com temas relacionados à matemática, estatística e computação.

Neste trabalho, é apresentado o relato de como se deu o desenvolvimento deste projeto e reflexões referentes a este processo.

\section{A experiência}

Com a homologação do projeto de extensão “ELAS na UTFPR$\mathrm{CP}^{\prime \prime}$ via edital da Pró-Reitoria de Relações Empresariais e Comunitárias (PROREC) da UTFPR, iniciou-se o exaustivo processo de firmar parcerias com colégios públicos do município de Cornélio Procópio, que possibilitassem o desenvolvimento do mesmo. A princípio a gestão e/ou equipe pedagógica dos colégios se mostravam abertos, porém ao perceberem que debates sobre gênero faziam parte da proposta, desencadeava uma série de resistências e negativas. É válido salientar que a cidade é bastante conservadora e que na época, outubro de 2017, a implantação do Programa "Escola sem Partido", iniciativa de grupos conservadores cujo principal alvo é a reflexão crítica sobre questões de gênero, estigmatizada como "ideologia de gênero" (MIGUEL, 2016), estava em pauta no estado do Paraná, com a volta da tramitação do Projeto de Lei 606/2016 na assembleia legislativa estadual, além da repercussão de casos como o de afastamento de educadores do Colégio Estadual Dom Geraldo Fernandes, da cidade de Cambé - PR, após polêmica envolvendo exposição de trabalho escolar de alunos 
retratando suicídio, aborto e pedofilia, temas esses que haviam sido escolhidos pelos próprios estudantes (ROSSINI, 2017).

Após este período de resistência firmou-se parceria com um colégio estadual da cidade. O projeto foi apresentado a direção do colégio e também a um dos professores de matemática, os quais se dispuseram a colaborar e apoiar a execução do mesmo pedindo como contrapartida um programa de monitoria de matemática, o qual foi inserido nas atividades do projeto. Posteriormente, o mesmo foi apresentado mais detalhadamente a toda equipe pedagógica e de gestão.

Em paralelo também ocorria o processo de seleção de estudantes dispostas a integrarem voluntariamente a equipe do projeto. E durante a seletiva ao serem indagadas sobre quais seriam as motivações para participarem do projeto foi unânime a questão de poucas mulheres nas carreiras de exatas (em especial a engenharia), estereótipos de gênero, bem como, a necessidade das mulheres ocuparem esses espaços, como ilustra a fala de uma das estudantes: "Mostrar que este também é um espaço para mulher na sociedade. Engenharia não é coisa de menino."

Com a parceria firmada e equipe formada iniciou-se a divulgação do projeto junto aos alunos e alunas do colégio parceiro. Inicialmente a apresentação do projeto como um todo (oficinas e monitoria) foi feita aos estudantes do $3^{\circ}$ ano do Ensino Médio, público alvo da proposta, e aos alunos do Ensino Fundamental II ( $6^{\circ}$ ao $9^{\circ}$ ano) foi difundida apenas a monitoria de matemática. Na atividade com a turma de Ensino Médio, como forma de despertar o interesse e explicar o funcionamento das oficinas e de algumas alternativas que seriam utilizadas nas mesmas, foram expostos e permitido o contato com robôs (Figura 1) construídos a partir do kit educacional LEGO Mindstorms®, muito utilizado para o ensino de lógica de programação e para o desenvolvimento de raciocínio lógico, devido a facilidade da linguagem de programação em blocos fornecida pela plataforma LEGOß. E ficou nítido o maior entusiasmo e proximidade por parte dos meninos e o estranhamento e desinteresse da maioria das meninas. Aproveitou-se a 
situação para conversar sobre a baixa representatividade feminina na área de exatas e sobre algumas razões que podem estar relacionadas, assim como, para explicar o porque as oficinas técnicas do projeto eram voltadas exclusivamente as alunas e realizar a inscrição das interessadas. Foram um total de 17 alunas inscritas.

Figura 1 - Robô LEGO Mindstorms ${ }^{\circledR}$

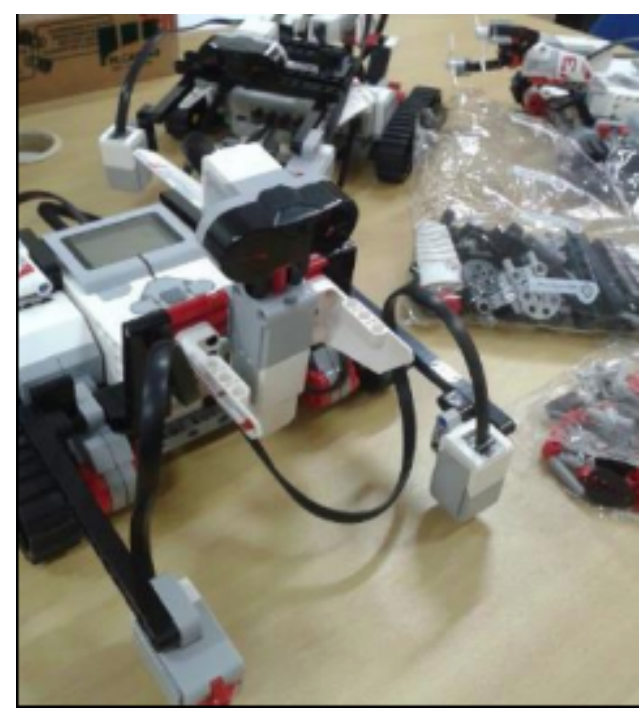

Após duas semanas, deu-se início às atividades com os estudantes do colégio, a princípio seguindo o planejamento das oficinas técnicas serem realizadas na UTFPR em decorrência da infraestrutura e para que as alunas tivessem um maior contato com ambiente acadêmico, intercaladas com as oficinas de gênero, que seriam abertas a todos, independente do gênero, e realizadas no próprio colégio em contraturno. Além das monitorias de matemática oferecidas semanalmente no colégio.

A primeira oficina técnica realizada foi uma visita guiada ao câmpus Cornélio Procópio da UTFPR em que as estudantes do ensino médio puderam conhecer um pouco mais do cotidiano da universidade, 
sua estrutura, cursos e projetos desenvolvidos, como o Procobaja ${ }^{2}$, que tem objetivo a criação de um veículo off-road (fora de estrada) com as melhores tecnologias de mecanização, contribuindo com a inovação aplicada à engenharia da mobilidade; Abutres Aerodesign ${ }^{3}$ que visa aproximação dos estudantes de engenharia do mercado aeronáutico e Equipe Rocket ${ }^{4}$ no qual são desenvolvidos foguetes de alta potência. É importante ressaltar que estes projetos foram apresentados pelas mulheres que os integram fortalecendo a questão da representatividade feminina.

Nessa primeira oficina houve uma baixa participação das alunas do colégio, apenas 4 compareceram, e dentre as várias justificativas para a ausência, as estudantes informaram que tiveram algum problema de saúde, trabalho ou outras atividades extra curriculares. Entretanto, apesar do número pequeno de participantes houve grande interação e interesse das mesmas acerca da vida acadêmica e dos diversos cursos de graduação do câmpus.

A segunda oficina técnica realizada foi a de Otimização. Nesta, somente 1 aluna compareceu, mas foi possível a realização da oficina, a qual fluiu muito bem, com demonstração de interesse da estudante, trocas entre esta e as integrantes da equipe do projeto.

Nas oficinas seguintes não houve participação dos estudantes, nem mesmo nas oficinas de gênero que seriam oferecidas no próprio colégio. Salientando, que em todo este processo reforçou-se o convite para a participação das oficinas, as datas, horários e locais eram relembrados através de um grupo de Whatsapp composto por estes alunos e as coordenadoras do projeto.

Diante disto, a equipe do projeto juntamente com a administração do colégio deu início a elaboração de estratégias para incentivar a participação dos estudantes nas oficinas. Assim, houve

\footnotetext{
2 https://www.facebook.com/procobaja/

${ }^{3}$ http://abutresaerodesign.wixsite.com/abutresutfprcp

${ }^{4}$ https://www.facebook.com/erocketutfpr/
} 
novamente visitas ao colégio para divulgação do projeto e abertura de novas inscrições para as atividades, as quais não surtiram efeitos. O que implicou na reformulação das oficinas para que as mesmas fossem desenvolvidas no próprio colégio em horários de aula, o que exigiu uma readequação do quadro de horários da escola e também do público alvo, já que não foi possível colocar a ideia em prática com as turmas de ensino médio e nem a separação por gênero.

Após este processo foi possível a realização das oficinas de lógica de programação com estudantes do ensino fundamental. De acordo com o relato das estudantes voluntárias do projeto, o desenvolvimento dessas oficinas foi um pouco conturbado devido a problemas de comunicação interna do colégio, a administração apesar de estar ciente das informações necessárias para o desenvolvimento das atividades nem sempre as repassava corretamente para a equipe pedagógica e docentes gerando imprevistos como, número excedente de alunos nas oficinas e mudança das turmas que seriam atendidas, dentre outros. Também é importante ressaltar que nesse novo formato houve resistência e negativa a realização das oficinas de gênero, alegando a mudança do público alvo e possíveis atritos com responsáveis pelos alunos e alguns professores. Evidenciando o que aponta Junqueira (2012), que o currículo escolar é um campo de permanentes disputas e negociações em torno de disposições, princípios de visão e de divisão do mundo e das coisas - especialmente das que concernem ao mundo da educação escolar e às figuras que o povoam e, ali, (re)definem sentidos e (re)constroem significados. E reforçando a postura de uma educação politizadora, que segundo Giroux (2003), sugere uma visão e prática de educação conservadora com um discurso de neutralidade e de negação da tomada de consciência das relações de poder envolvidos, recusando a abordar uma agenda política.

Por outro lado, a frequência não foi um problema nas monitorias de matemática com os estudantes do ensino fundamental. De acordo com os relatórios das monitoras, eram atendidos em média 10 alunos semanalmente, sendo a maioria meninas. Estes apresentavam grandes 
dificuldades em conteúdos básicos, como a realização das quatro operações (soma, subtração, multiplicação, divisão), que os atrapalhavam na compreensão dos conteúdos das séries em que estavam inseridos e contribuia na dispersão dos mesmos nas aulas e numa não rotina de estudos.

Dada a conturbada realização das oficinas técnicas, a não efetivação das oficinas de gênero e a majoritária presença feminina nas monitorias, passou-se a utilizar as monitorias de matemática para além do auxílio na compreensão dos conteúdos e exercícios propostos, e também como espaço de discussão em torno de papéis de gênero e divisão sexual do conhecimento e trabalho. Isso se deu através de conversas informais entre as monitoras e os estudantes. É importante evidenciar que ao longo de todo o projeto as monitoras e demais voluntárias participaram de ações formativas sobre temáticas de gênero e de como abordá-las.

Ao final do projeto foi promovida uma dinâmica com as alunas que participaram das monitorias, que consistia numa roda de conversa sobre diferentes possibilidades de se aprender matemática, estereótipos e expectativas de gênero, e a aplicação de um questionário com perguntas relacionadas. A conversa foi bastante produtiva, houve grande interação das alunas, as quais se mostraram interessadas em debater mais sobre os temas e também sobre novas alternativas de se aprender matemática, como lógica de programação e robótica.

\section{O questionário}

O questionário aplicado às alunas participantes da monitoria de matemática era composto pelas seguintes perguntas:

1. Existem coisas só de meninos e outras só de meninas? Dê exemplo.

2. Você acha que existe profissões de meninas e de meninos? Por quê? 
3. Na escola, qual matéria você mais gosta? Por quê?

4. E qual matéria você acha mais difícil? Por quê?

5. Você já sofreu bullying na escola por ser menina?

6. Você já ouviu alguém dizer "ah, você não pode fazer isso por que você é menina"?

7. Você já desistiu de fazer alguma coisa por ser menina?

8. Você já pensou em fazer engenharia?

9. Você acha que engenharia é profissão de meninos?

10. Você conhece alguma engenheira (mulher)?

Sem se identificar, 8 meninas de 11 a 13 anos, responderam estes questionamentos, e a seguir são apresentados alguns apontamentos sobre estas respostas.

Pergunta 1: 2 alunas não responderam, 4 afirmaram que sim e 2 que não. E o exemplo utilizado por uma das alunas para justificar que sim, há "coisas de menino" e "coisas de menina": "Sim. Na escola o professor de Educação física faz grupos de meninos e grupo de meninas.", chama a atenção, como bem salienta Junqueira (2012), que a escola é também um espaço de circulação de preconceitos, os quais são cotidianamente consentidos, cultivados e ensinados, produzindo efeitos sobre todos/as.

Pergunta 2: todas as alunas responderam que não e as justificativas podem ser sintetizadas em uma das respostas: "Porque não existe uma limitação nas profissões." Relacionando com a pergunta anterior, é possível observar que segundo essas alunas, a estereotipação de gênero apontada pela maioria na questão 1 não tem interferência no campo profissional.

Pergunta 3: metade das estudantes indicaram a disciplina de Ciências como favorita, com argumentos como: “(...) nós aprendemos coisas muito legais", "Porque fala sobre coisas muito interessantes", 
"Porque é legal estudar células, bactérias e etc." E a outra metade diversificou entre História, Línguas e Matemática, e as justificativas foram relacionadas a gosto pessoal e anseios futuros.

Pergunta 4: 6 das estudantes apontaram a Matemática como disciplina mais difícil e as justificativas se relacionam com números e cálculos: "Porque é vários tipos de conta", "Porque tem números e me confundo", "Porque tem muitos cálculos", “(...) muitos números e etc." Aqui é válido se questionar o porquê a maioria dos frequentadores dessas monitorias são meninas, da aversão da maioria delas a números e cálculos e o que houve no processo educativo dessas alunas. Muitos fatores podem estar relacionados a esses questionamentos, como uma socialização que secundariza o feminino e suas especificidades, em que meninas crescem sendo desestimuladas, direta e indiretamente, no contexto do desenvolvimento matemático, assim como, a internalização e perpetuação dessa socialização através de discursos e atitudes de professores, os quais podem desencorajar e silenciar meninas em aulas de matemática, como apontam os estudos de Casagrande e Carvalho (2012) e Santos e Cardoso (2012). Não foi feito um maior aprofundamento destes aspectos, no entanto, ao longo das monitorias surgiram por parte das alunas críticas referentes a postura e metodologia do professor de matemática do colégio, além de relatos das monitoras de questionamento da capacidade delas por parte do mesmo, e outras situações preconceituosas protagonizadas pelo docente e presenciadas pela coordenação do projeto.

Pergunta 5: apenas uma estudante indicou ter sofrido bullying no ambiente escolar por ser menina, mas não foi apresentado nenhum detalhamento sobre a situação.

Pergunta 6: apenas 1 estudante respondeu que não justificando que "Não, porque eu não deixo dizer, quando falarem isso pra mim eu vou fazer." As demais afirmaram que sim, destas 2 responderam que isso ocorreu na escola, em aula de educação física: "Sim, na escola no futebol", "Sim. Um professor falou que eu era fraca e mandou eu dar a bola para um menino.", trazendo novamente a escola como um 
ambiente de reprodução de estereótipos de gênero. É válido ressaltar que estas não identificaram essas situações como bullying na escola por serem meninas, o que reforça a naturalização de opressões de gênero no contexto escolar.

Pergunta 7: nessa pergunta as respostas se dividem, metade diz que sim e outra diz que não. E apenas uma aluna informou o que deixou de fazer: "Jogar futebol, porque não sou boa." O que provoca a indagação se esse juízo de valor não está relacionado ao fato do futebol ser geralmente associados aos homens.

Pergunta 8: mesmo considerando matemática uma disciplina difícil, 5 das alunas responderam que já pensaram em fazer engenharia.

Perguntas 9 e 10: apenas 1 uma aluna considera engenharia como uma profissão de homens, curiosamente essa mesma aluna respondeu que não há profissão de meninos e profissão de meninas. E a maioria delas, 5 alunas, afirmaram que conhecem ao menos 1 engenheira.

\section{Considerações finais}

O presente trabalho traz o relato de experiência do desenvolvimento de um projeto que nasceu das percepções e indagações de um grupo de educadoras, atuantes no ensino superior, acerca da divisão sexual nas ciências exatas e em profissões relacionadas, como por exemplo, a engenharia, e do anseio de levar essas discussões para o ambiente escolar.

Desenvolvimento este bastante conturbado e com um grande enfrentamento já descrito por Paraíso (1997): "gênero é campo de silêncio do currículo formal", não há espaço para discussões e desconstruções referentes a gênero no âmbito escolar. A escola segue como um ambiente de reprodução de categorias normatizantes do que é feminino e masculino, podando meninas do acesso a experiências e conhecimentos. E é urgente que estes espaços sejam abertos. 
Conseguiu-se abrir uma brecha em uma das ações do projeto que de certo modo é fruto do silenciamento enfrentado, as monitorias de matemática, e algumas sementes foram plantadas junto às alunas. No entanto, é preciso ir além, investir na formação dos professores, equipe pedagógica e de gestão escolar sobre a relevância de se discutir gênero nas escolas, de como a escola é um vetor de reprodução de preconceitos. Uma tarefa árdua, uma vez que se vai contra estruturas de poder, porém necessária para a construção de uma educação emancipadora, não impregnada de hierarquias sexuais e de livre acesso ao conhecimento.

\section{Referências}

CASAGRANDE, Lindamir Salete; CARVALHO, Marília Gomes de. Por que silenciadas e invisibilizadas? Relações de gênero nas aulas de matemática. Tecnologia e Sociedade, Curitiba, v. 8, n. 15, p. 103-114, 2012.

GIROUX, Henry A. Atos Impuros. Porto Alegre: Artmed, 2003.

JUNQUEIRA, Rogério Diniz. A Pedagogia do Armário: heterossexismo e vigilância de gênero no cotidiano escolar. Revista Educação On-line PUC-Rio, Rio de Janeiro, n. 10, p. 64-83, 2012.

MIGUEL, Luis Felipe. Da "doutrinação marxista" à "ideologia de gênero" - Escola Sem Partido e as leis da mordaça no parlamento brasileiro. Revista Direito e Práxis, Rio de Janeiro, v. 7, n. 15, p. 590-621, 2016.

PARAÍSO, M. A. Gênero na formação docente: campo de silêncio no currículo? Caderno de Pesquisa, Belo Horizonte, n. 102, p. 23-45, 1997.

ROSSINI, Andreza. Diretor e professora são afastados após polêmica com exposição em escola. Paraná Portal. Disponível em: https:/ / paranaportal.uol.com.br/cidades/exposicao-em-escola/. Acesso em 26 ago. 2020.

SANTOS, Jailma; CARDOSO, Lívia de Rezende. Relações de gênero na educação matemática dos anos iniciais do ensino fundamental. In: Colóquio Internacional "Educação e Contemporaneidade", 6. , São Cristóvão, 2012. 